\title{
Ethical problems in respiratory care: the role of the law
}

\author{
M A Branthwaite
}

It is customary-albeit perhaps simplistic - to identify four ethical principles as the basis for good medical practice. ${ }^{1}$ These are beneficence, non-maleficence, respect for autonomy, and justice, primarily distributive justice. The challenge for the practising clinician is to determine a proper course of action when these principles conflict, particularly when the individual, social, or financial consequences of new and perhaps promising treatments are known incompletely. Decisions taken in good faith are now often subject to public comment or criticism, and the National Health Service and other legislation add further constraints by introducing new rights or prescriptive guidelines without necessarily identifying the resources to fulfil these obligations. Many of these concerns have been part and parcel of medical practice for centuries, but it is only recently that the aura of the always wise and caring practitioner has been challenged by an increasingly assertive and vociferous public, ready to seek legal redress for perceived or actual wrongs. There is, of course, no sound reason why judicial decisions are any more cogent on matters of ethical principle than those of the medical profession, but society has created a legal system to regulate the conduct of its members and empowers the judiciary to resolve conflict. Any consideration of the moral basis of medical practice must therefore also take account of judicial determination of those questions of principle which have reached the courts. Examples of ethical conflict spawned by lung disease are considered here in the light of decisions made by the English courts.

The surgical management of lung cancer is a good example of potential conflict between beneficence and non-maleficence. Surgery is painful and entails risk. Is this "maleficence" warranted by the anticipated "beneficence" of disease alleviated or even cured? The practitioner develops a trained enthusiasm to advocate treatment aimed at prolonging life but does this sometimes over-rule the hesitation of a patient who, often of more mature years, may well see the prospect of death and dying in less threatening terms? An adult of sound mind, suitably informed, is perhaps the best arbiter for him or herself, but is the information always conveyed impartially? Subtleties of language or emphasis are likely to reflect the practitioner's view and there is, in any case, an expectation that the expert will advise. Once a decision to operate has been taken, questions of distributive justice as well as the balance between beneficence and maleficence may also be raised, particularly if prolonged intensive care is provided to treat complications which are likely to prove fatal in any event.
Such conflicts are an inevitable part of the management of any life threatening disorder where treatment, if available at all, is hazardous, unpleasant, or of limited benefit. The paucity of legal claims arising from the management of lung cancer suggests they are accepted, almost without challenge, by both practitioners and patients.

Decisions to withhold treatment, including immediately life saving measures such as mechanical ventilation, create similar ethical conflicts. However, even fully informed patients or relatives are far less willing to accept a recommendation against treatment, even when made in good faith and explained by a clinician seeking to act in the patient's best interest. Should the practitioner acquiesce and provide treatment - expensive, unpleasant, or even hazardous treatment such as surgery or chemotherapy - contrary to the clinician's perception of the patient's best interests? Can this be justified on the grounds of providing mental succour for a patient unable to accept the inevitability of death? If such action is permissible in private practice, does it contravene the principle of distributive justice if resourced from the NHS? Such difficult decisions rarely enter the public domain except when parents challenge a decision to withhold treatment from a child. Applications for a declaration that a particular treatment must be provided are most unlikely to succeed ${ }^{2}$ and the court will not seek to compel a practitioner to provide treatment contrary to that practitioner's genuine and sincerely held opinion of the patient's best interest. $^{3}$

The courts have shown a similar reluctance to interfere with decisions which involve resource allocation-distributive justicewhether this be the availability of routine treatments ${ }^{4}$ or innovative but expensive options of unverified merit. ${ }^{5}$ While it is reassuring to have legal backing for a particular decision subject to challenge, the ethical dilemma of how best to allocate scarce resources in general has largely remained with clinicians. Recommendations from the National Institute for Clinical Excellence (NICE) ${ }^{6}$ are a first step to transferring this invidious responsibility to an independent and authoritative body. Its decisions may be criticised, deemed too prescriptive, or prove unwarranted, but a nationally acknowledged policy must surely be more just than post code prescribing, however well intentioned.

An entirely different conflict between the interests of one individual and another is created by the introduction of new technologies. A prime example is transplantation. It is widely accepted, in the western world at least, that the removal of organs from a heart beating 
cadaver contravenes no moral principles because the donor is deemed to be dead. The recipient benefits from the loss of another. Implicit within the decision to recruit a patient to the transplant waiting list is the wish-or hope-that an unknown person of appropriate characteristics will die so that the recipient may live- or at least have a chance to live. Harm is suffered by one for the benefit of another. The nature of the harm suffered by the donor, be it a natural disease process or the consequence of a human act, is irrelevant. Beneficence can only be secured by harm-possibly maleficence (wrong doing) - to another.

There is no boundless supply of cadaveric donor organs and so attention has turned to alternative sources. A preliminary trial of mechanical ventilation to preserve physiological equilibrium in patients expected to develop the criteria of brain stem death in a matter of hours or days was terminated because legal advice (not a judicial decision) was that such treatment would be unlawful. ${ }^{7}$ The reason given was that mechanical ventilation was not in the best interests of the potential donor and, indeed, could be positively detrimental if, by preserving physiological equilibrium, an otherwise fatal neurological condition resulted instead in persistent vegetative state. A similar conflict between harm to the donor and benefit to the recipient is posed by the removal of healthy organs from adults for donation to their children, the maintenance to term of a pregnancy in which the fetus (a potential organ donor) is known to be anencephalic, or even the cloning of tissue for transplantation from harvested fetal material. The underlying moral principle is the Kantian philosophy that persons are an end in themselves and should not be treated as a means to an end. Do some living organisms - the fetus, the anencephalic, the nearly brain dead adult, or even the convicted criminal $^{8}$ - have such little value that they lie outside this provision?

To what extent is it possible to negate at least some of this moral uncertainty by invoking autonomy? A child's parent may implore the practitioner to transplant an organ but is such consent to being harmed legally valid? ${ }^{9}$ Can it be argued that the physical harm is negated by the psychological benefit of saving the life of one's own child? Would it be a step too far to impose donation of a non-regenerating organ on a twin sibling below the age of valid legal consent? If consent is all that is required to validate the removal of human organs for donation to another, why is it morally unacceptable to sell organs commercially if bodies, health, or even life can be sacrificed for personal and/or societal gain in other circumstances - for example, prostitution, hazardous employment, or military service?

It is tempting to promote xenotransplantation as an answer to this ethical dilemma but is there really a morally acceptable basis for killing members of other species-or breeding them intentionally - so that the sick of Homo sapiens can be cured? There may be social repugnance at breeding, for instance, infant chimpanzees as a source of donor organs, but mankind has not previously displayed undue deference to other species or their environment. The argument deployed to halt, or at least delay, the implementation of xenotransplantation was the potential risk of disease transmission and the possibility that this might be passed from one generation to another and hence threaten society as a whole..$^{10}$ Here the balance of ethical principles has changed again - the benefit is to the recipient and the harm is to a donor animal; human autonomy, at least for the index generation, has not been transgressed but justice for society as a whole may be under threat. Which interest should prevail? The very real possibility that unforeseen but highly damaging consequences can flow from new procedures has been brought into sharp focus by the epidemic of BSE and new variant CJD, and by the unexpected death of the recipient of trial gene therapy administered in a viral vector. ${ }^{11}$

Responsibility for unknown and possibly disastrous consequences is an integral part of research both in the physical and biological sciences. The need for informed consent-in other words, respect for autonomy-is accepted without question today but the practitioner must also consider the balance between beneficence and maleficence, both individually and for society as a whole. Nowhere is this more difficult than with research in children. A parent can give or withhold consent to medical treatment, but only if acting in the child's best interest. ${ }^{12}$ Parents are likely to want the best for their child, but how is "best" to be defined if research is precluded by lack of consent? ${ }^{13}$ The sincere enthusiasm of an investigator is likely to be conveyed to the parent, and the emotional circumstances in which therapeutic decisions must often be taken are a reminder of the need for exceptional care in obtaining demonstrably valid consent, even for therapeutic research on children. ${ }^{14}$

Non-therapeutic research is particularly difficult to defend in moral terms when undertaken on children, and possibly on any patient unable to give informed consent. Yet there are some circumstances such as vaccination in which benefit to society at the possible expense of the individual is accepted as valid. How then should progress be regulated? Pre-emptive legislation $^{15}$ is likely to be resented by the investigator as too constraining ("we will take our research overseas") but the unfettered opportunity to explore new developments is equally likely to spawn challenge through the courts or by the media ("experiments on tiny babies"). The speed with which society will accept developments which threaten moral instincts or prejudices depends in part on the confidence it places in those promoting change. In the current climate of suspicion towards the medical profession and the quality of its self-regulation, the innovative researcher would do well to recall the proverb "make haste slowly".

Recourse to the law has also been prompted by another common dilemma. Is it ever justified and, if so when, to withdraw treatment aimed at saving life or to prescribe treatment 
which may shorten life? There are several reasons why these questions probably arise more frequently in the management of respiratory disease than in any other discipline. Isolated ventilatory failure in otherwise stable patients can exist in the long term without risk to the individual provided mechanical ventilation is continued. Death follows cessation of treatment in stark temporal proximity. A less immediate but well recognised link also exists between death and the use of opiates to relieve the symptoms of terminal illness. Death in these circumstances is likely to be characterised by obtundation, absence of coughing, and shallow respiration-features also seen with opiate overdose. The association between treatment and death is particularly clear when opiates are used to relieve dyspnoea-a symptom which is common in lung disease, distressing and difficult to alleviate.

Once again the principles of beneficence, non-maleficence, and autonomy of the individual are the basis for the ethical decision, but the probable end point of the decision-death of the patient-is a matter which could raise allegations of homicide. A series of decided cases has made English law clear on the point, although there is still widespread pressure for change.

An allegation of homicide will only succeed if it can be established beyond reasonable doubt that the act of the defendant caused the death, both as a matter of fact and of law. Causation of death as a matter of fact is determined by application of the "but for" test. But for the act of the defendant, would the patient have died? The test may be satisfied if, for example, death follows within a few minutes of cessation of mechanical ventilation. However, causation in law requires analysis of the sequence of factors leading to death and does not necessarily accept that the last was determinative. Thus, in considering the legality of withdrawing mechanical ventilation from a patient with severe Guillain-Barré disease, a New Zealand court held that the cause of death was the disease, not the cessation of treatment. ${ }^{16} \mathrm{~A}$ similar view has been adopted in the English courts when considering appeals against convictions for murder or manslaughter where the victims had sustained severe cerebral damage and mechanical ventilation had been withdrawn. ${ }^{17}$ The greatest difficulty in refuting a causal link between the withdrawal of treatment and subsequent death is when the patient is physiologically stable. Withdrawal of nutrition and hydration from a patient in persistent vegetative state is the prime example. The House of Lords has held that the provision of nutrition and hydration by "artificial" means-for example, a gastrostomy - is "medical treatment" and not merely basic humanitarian care. Their Lordships concluded that there is no legal obligation to provide treatment which is futile or not in the best interests of the individual, or to treat a person so obtunded as to have no best interests. ${ }^{18}$ However, the House was not prepared for this decision to form a precedent for subsequent decisions. Approval by the court should therefore be sought whenever consideration is being given to the withdrawal of life sustaining treatment from a physiologically stable individual. ${ }^{19}$

The validity of prescribing treatment which may accelerate death has been handled on a different basis, again invoking the principles of the law of homicide. A conviction will only be obtained if it can be established beyond reasonable doubt that the defendant acted with a criminally culpable state of mind. Was there an intention to kill or cause serious injury? A man may intend to achieve an objective and set out to do so by whatever means lie within his power ("primary intent"). Intention must be carefully distinguished from motive. Intention is what the actor set out to achieve; motive is why he decides to do so. An intention to kill formulated in response to an honourable motive is no defence to a charge of murder. ${ }^{20}$

It is also possible at law to presume intention ("secondary intent") when a particular consequence is virtually certain and the actor is aware at the time of acting that this is so. The presumption can be rebutted on behalf of the practitioner accused of causing death by excessive opiate administration to the seriously ill by proving, to the satisfaction of the jury, that the intention was solely to relieve distress. ${ }^{21}$ The contribution of opiates to the death is accepted on the basis of double effect-an unwanted consequence or effect accepted as a necessary concomitant of a desirable objective. In moral terms this reasoning is open to question-not least because extraneous but contemporaneous pressures may be operating at the time end of life decisions are taken-for example, in a busy intensive care unit.

Thus, the law may have helped to clarify the practitioner's legal duty but conflict still arises. ${ }^{3}$ If there is a division of opinion on the futility of treatment, whose view should prevail? If practitioners are not obliged to institute or continue treatment which, in their bona fide clinical judgement is of no value, are they therefore justified in providing medication to relieve the perceived or anticipated distress of the dying patient, with or without his consent? Is it practical to obtain valid consent in the circumstances or would it create additional, unwarranted, and avoidable distress? At what point in an illness should the question be raised with the patient? What interval of time should be allowed to elapse before thought is given to the possibility of a change of mind? Greater use of living wills ${ }^{22}$ or implementation of the recommendation that "treatment attorneys" could be appointed by a competent adult to take decisions on their behalf if they become too mentally impaired to do so for themselves ${ }^{23}$ may help to avoid such conflict in the future.

The law has been described here as a practical means for "resolving" ethical conflicts in the sense that the law dictates what is and is not deemed to be acceptable practice. Sometimes, however, it is new law which creates the conflict. Reference has been made already to the recommendations of NICE, but health care providers are then left with the problem of how to allocate limited resources between competing needs when those requiring or requesting 
the recommended treatment can claim it "as of right". Similarly, there are predictions that the Human Rights Act 1998 which incorporated the European Convention on Human Rights into English law in October 2000 will provide claimants with a legislative basis on which to demand treatment as a "right to life", be protected from "inhuman or degrading treatment", or secure "respect for private and family life". Not withstanding the enthusiasm of some legal practitioners for the wealth of litigation which they anticipate this legislation will spawn, it should be noted that no new rights are provided by the Act; they are merely protected now by national as well as European law. Furthermore, there has been noticeable judicial disapproval of a number of attempts, made before the Act was even in force, to invoke its provisions as additional argument in favour of claims brought on other grounds. ${ }^{24}$ Similarly, if the recommendations of NICE do no more than define with greater precision what constitutes "a responsible body of medical opinion", the traditional legal test for defining the proper standard of care will not have been altered to a significant degree. Nor is there any new legal reason why research should be not be continued, provided it is conducted in accordance with principles accepted by the profession and, increasingly, by the judiciary.

The real anxiety created by this new legislation centres on distributive justice. Society is unlikely to accept all the implications of an obligation to provide everything possible for everyone in need. Conversely, individual members of society wishing to exercise their autonomy are already legally entitled to decline the provision of everything possible, including life saving treatment. ${ }^{25}$ If the individual or society choose to determine the balance between beneficence and maleficence, who are we to say otherwise?

1 Gillon R. Medical ethics: four principles plus attention to scope. BMF 1994;309:184-8.

2 R v Portsmouth Hospital NHS Trust [1999] Lloyds Law Reports: Medical 367-76.

3 Re J (a minor) [1993] 4 Medical Law Reports 21-7.

R v Secretary of State for Social Services ex parte Hincks (1992) 1 Butterworth's Medical Law Reports 93-7.

$5 \mathrm{R} v$ Cambridge Health Authority ex parte B (a minor) [1995] 6 Medical Law Reports 250-5.

6 Yamey G. Dobson backed NICE ruling on 'flu drug. BMF 1999;319:1024.

7 Riad H, Nicholls A, Neuberger J, et al. Elective ventilation of potential organ donors. BMF 1995;310:714-8.

8 Josefson D. Prisoner wants to donate his second kidney. BMF 1999;318:7.

9 R v Brown [1993] 2 Weekly Law Reports 556-609.

10 Kennedy IH. Report by the Advisory Group on the Ethics of Xenotransplantation. London: Department of Health, 1977 .

US halts gene tests after youth dies: effects of experimental treatment not known. The Guardian, 30 September 1999. 2 Re C (a minor). Medical treatment: refusal of parental conRe C (a minor). Medical treatment: refusal of
sent [1997] 8 Medical Law Reports 166-74.

13 Chambers TL. Seven questions about paediatric research. $\mathcal{F}$ $R$ Soc Med 2000;93:320-1.

14 Smith R. Babies and consent: yet another NHS scandal. $B M F$ 2000;320:1285-6.

5 Watson R. EU adopts tougher safeguards on genetic modification. BMF 1999;319:11.

16 Auckland Area Health Board v Attorney-General [1993] 4 Medical Law Reports 239-52.

17 R v Malcherek; R v Steel [1981] 2 All England Reports $422-9$

18 Airedale NHS Trust v Bland [1993] 4 Medical Law Reports 39-75.

19 Wade DT, Johnston J. The permanent vegetative state: practical guidance on diagnosis and management. BMF 1999;319:841-4.

20 R v Cox (1992) 12 Butterworths Medical Law Reports 38-49.

21 Dyer C. British GP cleared of murder charge. BMF 1999;318:1306.

22 British Medical Association. Withholding and withdrawing life-prolonging medical treatment: guidance for decision making. London: BMJ Publishing Group, 1999.

23 Dyer C. Adults will be able to appoint proxies to make health decisions. BMF 1999;319:1218.

24 R v NW Lancashire Health Authority ex parte A, D \& G 1999) The Times, 24 August.

25 Re MB [1997] 8 Medical Law Reports 217-28. 